human fetal hormones. J. Clin. Invest., 51: 3080 (1972).

9. Levina, S. E.: Endocrine features in development of human hypothalamus, hypophysis, and placenta. Gen. Comp. Endocrinol., 11: 151 (1968)

10. Perks, A. M. and Vizsolyi,E.: Studies of the neurohypophysis in foetal mammals. In: K. W. Cross, G. S. Davies, and P. W. Nathanielsz: Foetal and Neonatal Physiology, p. 430 (Cambridge University Press, London, 1973).

11. Skowsky, W. R., Bashore, R. A., Smith, F. G., and Fisher, D. A.: Vasopressin metabolism in the foetus and newborn, In: K. W. Cross, G. S. Davies, and P. W. Nathanielsz: Foetal and Neonatal Physiology, p. 439 (Cambridge University Press, London, 1973).

12. Skowsky, W. R., and Fisher, D. A.: Fetal neurohypophyseal arginine vasopression and arginine vasotocin in man and sheep. Pediat. Res., 11: 627 (1977).

13. Skowsky, W. R., Rosenbloom, A., and Fisher, D. A.: Radioimmunoassay of arginine vasopressin development and application. J. Clin. Endocrinol. Metab., 38: 278 (1974)
14. Vizsolyi, E., and Perks, A. M.: New neurohypophyseal principle in foetal mammals. Nature (London), 223: 1169 (1969)

15. Weitzman, R. E., and Fisher, D. A.: Log linear relationship between plasma arginine vasopressin and plasma osmolality. Amer. J. Physiol., 233: E37 (1977).

16. Weitzen, R. E. Fisher, D. A., DiStefano, J. J., III, and Bennett, C. M.: Episodic secretion of arginine vasopressin. Amer.J. Physiol., 233: E32 (1977).

17. Ms. Chris Sessions and Ms. Che-Ching Wang provided excellent technical assistance. Ms. Mary Badenoch prepared the manuscript.

18. This research was supported by USPHS Grants HD-06335 and HD-08953 from NICHHD, NIH.

19. Requests for reprints should be addressed to: Richard E. Weitzman, M.D., Harbor General Hospital, Building A-17, 1000 West Carson Street, Torrance, California 90509 (USA).

20. Received for publication January 7,1977

21. Accepted for publication April 26, 1977.

Printed in U.S.A.

Aminophylline breathing cortisol lung lavage fluid

oxygen

premature

\title{
Effects of Cortisol and Aminophylline upon Survival, Pulmonary Mechanics, and Secreted Phosphatidyl Choline of Prematurely Delivered Rabbits
}

\author{
CYNTHIA T. BARRETT, ${ }^{(26)}$ ALEX SEVANIAN, DALE L. PHELPS, CARL GILDEN, AND \\ SOLOMON A. KAPLAN \\ Department of Pediatrics, UCLA School of Medicine, Los Angeles, California, USA
}

\begin{abstract}
Summary
Rabbits delivered at 27.0 days of gestation were studied after administration of cortisol $(2 \mathrm{mg} / \mathrm{kg} / \mathrm{day})$, aminophylline $(6.25$ $\mathrm{mg} / \mathrm{kg} / \mathrm{day})$, or sterile saline to the does on days 24-26 of gestation. Survival at $60 \mathrm{~min}$ was $52.9 \%$ in the aminophyllinetreated group and $22.2 \%$ in the control and cortisol-treated groups with all animals being in a warm, oxygen-enriched environment and receiving frequent tactile stimulation. Lung volume at $30 \mathrm{~cm} \mathbf{H}_{2} \mathrm{O}$ was lower in the cortisol-treated group than in the controls or aminophylline-treated group in animals surviving for $60 \mathrm{~min}$ (Table 2). The aminophylline-treated group retained significantly more gas at low pressures on the deflation curve (Table 2) and had significantly more phosphatidylcholine recovered in lung lavage fluid (Table 3) than the other groups. Aminophylline appears to have enhanced lung maturation better than cortisol in this experimental model.
\end{abstract}

\section{Speculation}

Improved survival of prematurely delivered rabbits after aminophylline administration (as compared with cortisol) may be due to a combination of factors including enhanced maturation of the lungs as well as stimulation of the respiratory center.

Accelerated maturation of fetal mammalian lungs as evidenced by physiologic and biochemical measurements is now well known to occur after antepartum administration of glucocorticoids. In addition, decreased morbidity from RDS and improved survival of prematurely born human infants has been reported by Liggins and Howie (13) when glucocorticoids have been administered at least $24 \mathrm{hr}$ before delivery. Motoyama and his co-investigators (15) reported that after antenatal administration of glucocorticoids some rabbits delivered at 27 days of gestation were able to breathe, but control animals did not breathe until 28 days. The treated animals, in addition, retained more air at low pressures and had better lung fluid bubble stability than the controls. Taeusch and his coworkers (21) reported increased survival of rabbits delivered at 28 days of gestation in the first $6 \mathrm{hr}$ after delivery after direct fetal administration of hydrocortisone. Lung pressure-volume measurements indicated that lung stability as measured by the percentage of total lung volume retained during deflation at 10 $\mathrm{mm} \mathrm{Hg}$ increased with increasing survival.

Although augmented production of corticosteroids is probably one mechanism by which fetal lungs mature normally, the pharmacologic doses used to stimulate accelerated maturation may have deleterious effects upon the fetuses so treated. Mothers with eclampsia treated with betamethasone have increased antenatal mortality compared with controls (13); animal studies indicate that corticosteroids may compromise placental function (23) and also cause temporary inhibition of lung growth (5, 11). In addition, glucocorticoid administration may be accompanied by reduced cell numbers in the brain and by disturbances of myelination, synaptic growth, and locomotor ability $(9,19)$.

For these reasons our laboratory has been investigating some mechanisms by which corticosteroids accelerate lung maturation in an attempt to identify a pharmacologic agent with less 
potential toxicity than cortisol and the same maturational effects upon lung surfactant.

We have previously reported that aminophylline augments tissue cyclic AMP by inhibition of cyclic AMP phosphodiesterase and increases incorporation of labeled precursors into phosphatidylcholine to the same extent as glucocorticoids (2). Karotkin et al. (10) have also demonstrated accelerated lung maturation after antenatal administration of aminophylline. Studies of the survival of prematurely delivered animals, as a measure of lung maturation, have not been reported following antenatal administration of aminophylline.

The present study was undertaken to examine the comparative effects of antenatal administration of aminophylline and hydrocortisone to prematurely delivered rabbits placed in a warm oxygen-enriched environment and given tactile stimulation to promote breathing. Survival during the first hour, lung pressurevolume relationships, and phospholipids recovered from tracheal washes after spontaneous or induced death were determined.

\section{MATERIALS AND METHODS}

Rabbits with time of mating known to within $3 \mathrm{hr}$ were used for all studies: zero time was arbitrarily assigned to the beginning of the 3-hr mating period.

In the initial phase of the study control rabbits (with no surgical intervention) were delivered by cesarean section at 27.0 , $27.5,28.0$, and 28.5 days of gestation to determine at what age viability was less than $50 \%$. After delivery all rabbits were dried immediately, placed in an isolette at $32^{\circ}$ with an environmental oxygen concentration of $32 \%$, and stimulated frequently by handling.

After completion of these preliminary observations, experiments were carried out in which the pregnant does were injected with saline, hydrocortisone, $2.0 \mathrm{mg} / \mathrm{kg} /$ day sc or aminophylline, $6.25 \mathrm{mg} / \mathrm{kg} /$ day iv on days 24-26 of gestation as has been previously described (2). A total of 27 control, 35 aminophylline-treated, and 36-hydrocortisone-treated fetuses were delivered with four does in each group.

The does were lightly anesthesized with Diabutal Na pentobarbital and as soon as asleep were killed with intravenous $\mathrm{KCl}$ followed by immediate delivery. Elapsed time from onset of anesthesia to delivery of the first rabbit was less than $2 \mathrm{~min}$ in all instances. After delivery the rabbits were all treated as described above. Death was defined by absent response to tactile stimulation and apnea for $5 \mathrm{~min}$. All deaths which occurred in each 15-min period were summed together. All animals alive at $60 \mathrm{~min}$ after delivery were killed with an intraperitoneal injection of diabutal for further studies. Our experience indicates that prematurely delivered rabbits which survive for $1 \mathrm{hr}$ almost invariably survive for several days with meticulous neonatal care. Weights and lengths were determined for all animals. The personnel handling the newly born animals were not aware of whether the animals were controls or had received hydrocortisone or aminophylline.

After death, the tracheas of selected animals dying at less than $30 \mathrm{~min}$ or more than $60 \mathrm{~min}$ of age were cannulated with fine polyvinyl catheters through small neck incisions and the lungs were de-gassed by placing the whole animal in a vacuum chamber at approximately $12 \mathrm{~mm} \mathrm{Hg}$ for 2 -min periods repeated three times. Pressure-volume relations were determined by connecting the tracheal cannulae to a calibrated water manometer and a $10-\mathrm{ml}$ syringe by a $\mathrm{T}$-tube. Corrections were made for volume changes in the dead space which occurred with the changes of pressure. The volume of air in the lungs after 2 min at $30 \mathrm{~cm} \mathrm{H}_{2} \mathrm{O}$ was defined as maximal lung volume. Volumes on deflation at $4 \mathrm{~cm}$ and $10 \mathrm{~cm} \mathrm{H}_{2} \mathrm{O}$, expressed as a percentage of maximal lung volume, were calculated for each study.

After these measurements were made the lungs of each fetus were lavaged with a total volume of $5 \mathrm{ml}$ of sterile saline in aliquots slightly less than the measured lung volume at $30 \mathrm{~cm}$ $\mathrm{H}_{2} \mathrm{O}$. These washings were cooled to $4^{\circ}$ in an ice bath and centrifuged at $500 \times g$ for $10 \mathrm{~min}$ to remove cell debris. The supernatant was then frozen and lyophilized at $-30^{\circ}$. The dried residue was suspended in $6 \mathrm{ml} \mathrm{2:1} \mathrm{chloroform-methanol} \mathrm{and}$ the lipids were extracted according to the method of Folch (6). Total lipids recovered by the above procedure were further fractionated by thin layer chromatography on silica gel H-coated plates which were developed in chloroform-methanol-water in the proportions $65: 25: 4$; the various lipids were visualized under ultraviolet light after spraying the plates with an $0.1 \%$ dichlorofluorescein reagent. The spots corresponding to phosphatidylcholine were scraped off and the lipids were washed from the silica gel using chloroform, methanol, acetic acid, and water in proportions 50:39:1:10, after which the dye was removed by mixing with $4 \mathrm{~N} \mathrm{NH}_{4} \mathrm{OH}$ and extracting the upper aqueous phase (1). The content of phosphatidylcholine was determined by phosphorus analysis according to the method of Bartlett (3). The fatty acid composition of phosphatidylcholine was determined by reaction with $0.5 \mathrm{~N} \mathrm{HCl}$ in methanol under nitrogen at $80^{\circ}$ for $4 \mathrm{hr}$ in sealed ampules. The resulting fatty acid methyl esters were extracted into heptane for injection into a gas-liquid chromatograph (Perkin-Elmer model 881) fitted with a 10 -foot column containing $12 \%$ diethylene glycol succinate. Characterization and quantitation of the individual fatty acid methyl esters was performed by comparison with standard fatty acid methyl esters obtained from Applied Sciences Lab.

Statistical analyses of the results were performed using Student's $t$-test (20).

\section{RESULTS}

Under the conditions of the present study, with rapid delivery of the rabbits into a warm oxygen-enriched environment in which they received considerable tactile stimulation, survival of the litters delivered at $27.5,28.0$, and 28.5 days of gestation was greater than $85 \%$, with greater than $50 \%$ survival at 24

Table 1. Survival at delivery and within next hour of rabbits delivered at 27.0 days of gestation after antepartum adminsitration of saline (control), cortisol, or aminophylline

\begin{tabular}{|c|c|c|c|c|c|c|}
\hline & \multicolumn{2}{|c|}{ Control' $^{1}$} & \multicolumn{2}{|c|}{ Cortisol $^{2}$} & \multicolumn{2}{|c|}{ Aminophylline ${ }^{3}$} \\
\hline & No. & $\begin{array}{c}\% \\
\text { Liveborn }\end{array}$ & No. & $\begin{array}{c}\% \\
\text { Liveborn }\end{array}$ & No. & $\begin{array}{c}\% \\
\text { Liveborn }\end{array}$ \\
\hline Alive at $30 \mathrm{~min}$ & 14 & 51.9 & 27 & 75.0 & 32 & 94.1 \\
\hline Alive at $45 \mathrm{~min}$ & 6 & 22.2 & 14 & 38.9 & 21 & 61.8 \\
\hline Alive at $60 \mathrm{~min}$ & 6 & 22.2 & 8 & 22.2 & 18 & 52.9 \\
\hline
\end{tabular}

${ }^{1}$ Total delivered, 27; liveborn $27(100 \%)$.

${ }^{2}$ Total delivered, 36; liveborn $36(100 \%)$.

${ }^{3}$ Total delivered, 35; liveborn $34(97.1 \%)$.



Fig. 1. Survival of rabbits delivered at 27.0 days of gestation during first hour after delivery following antenatal administration of aminophylline (solid line), cortisol (dashed line), or normal saline (dotted line) on days 24-26 of gestation. Survival is expressed as percentage of liveborn animals. 
and $48 \mathrm{hr}$ in each litter. In the present report all litters were delivered at 27.0 days of gestation for study of survival and lung mechanics.

All liveborn fetuses delivered in the three study groups, having received aminophylline, hydrocortisone, or saline antepartum, were vigorous and had good muscle tone at the time of delivery. All, in addition, made initial respiratory efforts. By 5 min of age many animals in all groups had irregular respirations, cyanosis, and little or no flexor tone, and some deaths within each study group had occurred by $15 \mathrm{~min}$ of age. Table 1 shows the numbers of fetuses in each group and their survival at 30 , 45 , and $60 \mathrm{~min}$. One stillbirth occurred in the 35 fetuses of the aminophylline-treated litters. Figure 1 illustrates that at all times the survival was greatest in the aminophylline-treated group. By $60 \mathrm{~min}$ of age the control and cortisol groups both had survival rates of $22.2 \%$, whereas survival in the aminophylline-treated group exceeded $50 \%$. Although most fetuses in each group had irregular respirations and poor tone in the first $30 \mathrm{~min}$, by $45 \mathrm{~min}$ most of the survivors had regular respirations, good color and tone, only mild retractions, and many had spontaneous movements. All surviving rabbits were killed between 60 and $75 \mathrm{~min}$ of age for further biochemical and mechanical studies of the lungs.

Control fetuses weighed $24.3 \pm 4.8 \mathrm{~g}(\mathrm{SD})$; those in the cortisol group weighed $20.0 \pm 3.4 \mathrm{~g}$, and those in the aminophylline group weighed $22.6 \pm 4.5 \mathrm{~g}$. The only significant differences are between the control and hydrocortisone groups $(P<0.001)$.

Results of pressure-volume measurements are shown in Table 2 for animals which died within the first $30 \mathrm{~min}$ after delivery and those which survived for $1 \mathrm{hr}$. Lung fluid analyses and pressure volume measurements were made on only one of the two fetuses dying before $30 \mathrm{~min}$ of age in the aminophyllinetreated group and, these values, therefore, were not utilized for statistical analysis. Lung volume at $30 \mathrm{~cm} \mathrm{H}_{2} \mathrm{O}$ in the aminophylline-treated animal dying at less than $30 \mathrm{~min}$ of age was more than $2 \mathrm{SD}$ greater than the mean of the control animals and more than 3 SD above the mean of the cortisol animals dying in the same time period; differences between the control and cortisol-treated animals were not significant at less than 30 min. Volume retained in the lung at $10 \mathrm{~cm} \mathrm{H}_{2} \mathrm{O}$, expressed as a percentage of total lung volume, was significantly (42.0 \pm $4.01 \%$ ) greater in the control than in the cortisol-treated group $(32.5 \pm 4.92)$ with the single aminophylline value of $37.9 \%$ being between the mean values of the other two groups. Greater differences of lung volumes and pressure-volume relationships were present in the animals which survived for more than 60 min. Lung volume at $30 \mathrm{~cm} \mathrm{H}_{2} \mathrm{O}$ was significantly less in the cortisol-treated group than in the control and aminophyllinetreated animals, which had similar volumes. During deflation, the aminophylline-treated lungs retained significantly more air than the control or cortisol lungs at both 10 and $4 \mathrm{~cm} \mathrm{H}_{2} \mathrm{O}$.

Total lung volume and its percentage retained at 4 and $10 \mathrm{~cm}$ $\mathrm{H}_{2} \mathrm{O}$ increased significantly with survival to $60 \mathrm{~min}$ in the control lungs. Mean changes in the cortisol-treated animals were similar but were not significant. Changes in the aminophylline-treated animals could not be evaluated because of the single measurement at less than $30 \mathrm{~min}$, but this value was within $1 \mathrm{SD}$ of mean values obtained from the animals surviving for $60 \mathrm{~min}$.

Table 3 shows the content of phosphatidylcholine in the lavage fluid obtained from the animals which survived for less than 30 or more than $60 \mathrm{~min}$. There were no significant differences in the amount of phosphatidylcholine obtained from the three groups at $30 \mathrm{~min}$, but at $60 \mathrm{~min}$ significantly more phosphatidylcholine was present in the lavage fluid from the aminophylline-treated groups. No significant differences in amount of phosphatidylcholine recovered were noted in animals dying at less than $30 \mathrm{~min}$ and those dying at more than $60 \mathrm{~min}$ of age. No significant differences were present in the percentage of lecithin containing palmitic acid either as a function of treatment group or as a function of survival time.

\section{DISCUSSION}

The methods used for the delivery and care of the rabbits were critical to the experiment for a number of reasons. The use of barbiturate anesthesia can result in respiratory depression

Table 2. Pressure-volume measurements from rabbits dying less than 30 min or more than 60 min after delivery in treatment groups after antenatal administration of saline (control), hydrocortisone, and aminophylline ${ }^{1,2}$

\begin{tabular}{|c|c|c|c|c|c|c|}
\hline & \multicolumn{2}{|c|}{ Control } & \multicolumn{2}{|c|}{ Hydrocortisone } & \multicolumn{2}{|c|}{ Aminophylline } \\
\hline & $\begin{array}{c}<30 \text { min } \\
(n=4)\end{array}$ & $\begin{array}{l}>60 \mathrm{~min} \\
(n=4)\end{array}$ & $\begin{array}{c}<30 \text { min } \\
(n=3)\end{array}$ & $\begin{array}{c}>60 \min \\
(n=5)\end{array}$ & $\begin{array}{c}<30 \min \\
(n=1)\end{array}$ & $\begin{array}{l}>60 \min \\
(n=13)\end{array}$ \\
\hline $\mathrm{V}_{30}$ & $1.23 \pm 0.47$ & $2.73 \pm 0.54$ & $1.06 \pm 0.35$ & $1.73 \pm 0.50$ & 2.32 & $2.83 \pm 0.68$ \\
\hline$V_{10} / V_{30}$ & $42.0 \pm 4.01$ & $55.4 \pm 4.55$ & $32.5 \pm 4.92$ & $52.2 \pm 13.30$ & 37.9 & $66.0 \pm 7.95$ \\
\hline$V_{4} / V_{30}$ & $21.8 \pm 4.15$ & $34.7 \pm 8.37$ & $12.3 \pm 6.81$ & $28.6 \pm 17.34$ & 14.6 & $48.2 \pm 12.42$ \\
\hline
\end{tabular}

${ }^{1}$ Lung volumes at $30 \mathrm{~cm} \mathrm{H} \mathrm{H}_{2} \mathrm{O}\left(\mathrm{V}_{30}\right), 10 \mathrm{~cm} \mathrm{H} \mathrm{H}_{2} \mathrm{O}\left(\mathrm{V}_{10 / 30}\right)$, and $4 \mathrm{~cm} \mathrm{H}_{2} \mathrm{O}\left(\mathrm{V}_{4 / 30}\right)$ expressed as percentage of total lung volume during deflation are recorded, all $\pm 1 \mathrm{SD}$ (except aminophylline $<30$ in which only one animal could be studied).

${ }^{2}$ Significance (see table below).

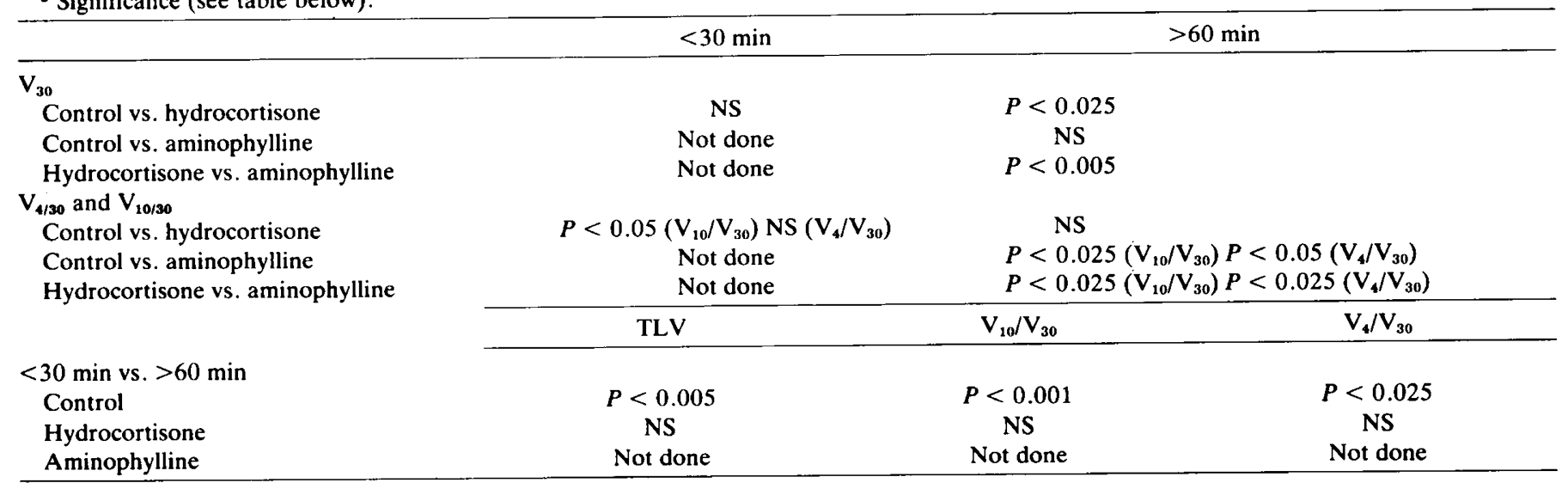


Table 3. Lung phosphatidylcholine (milligrams) recovered by lavage from rabbits dying less than 30 min or more than 60 min after delivery in treatment groups after antenatal administration of saline (control), hydrocortisone and aminophylline $(\text { mean values } \pm 1 S D)^{1}$

\begin{tabular}{|c|c|c|c|c|c|c|}
\hline & \multicolumn{2}{|c|}{ Control } & \multicolumn{2}{|c|}{ Hydrocortisone } & \multicolumn{2}{|c|}{ Aminophylline } \\
\hline & $\begin{array}{c}<30 \text { min } \\
(n=4)\end{array}$ & $\begin{array}{l}>60 \text { min } \\
(n=4)\end{array}$ & $\begin{array}{c}<30 \text { min } \\
(n=3)\end{array}$ & $\begin{array}{c}>60 \text { min } \\
(n=5)\end{array}$ & $\begin{array}{c}<30 \min \\
(n=1)\end{array}$ & $\begin{array}{l}>60 \text { min } \\
(n=13)\end{array}$ \\
\hline Phosphatidylcholine & $0.104 \pm 0.072$ & $0.236 \pm 0.122$ & $0.076 \pm 0.022$ & $0.171 \pm 0.066$ & 0.159 & $0.389 \pm 0.119$ \\
\hline
\end{tabular}

1 Significance, $<30 \mathrm{~min}$ vs. $>60 \mathrm{~min}$ : control, NS; hydrocortisone, NS; aminophylline, not done. Significance, <30 min: control vs. aminophylline, not done; control vs. hydrocortisone, NS; aminophylline vs. hydrocortisone, not done. Significance, $>60$ min: control vs. aminophylline, $P<0.05$; control vs. hydrocortisone, NS; aminophylline vs. hydrocortisone, $P<0.005$.

at birth if sufficient time is allowed for the drug to circulate and cross the placenta. With the methods we used for anesthesia and delivery no depression was observed in the rabbits, and all liveborn animals at the time of delivery had good tone and made respiratory efforts. By drying the animals and placing them in a warm environment, we were following time-honored neonatal practices to diminish evaporative heat losses following delivery. Since Budin (4) reported improved survival of prematurely born human infants cared for in a warm environment, numerous investigators have established that a neutral thermal environment in which oxygen consumption is at a minimum promotes better survival of the prematurely delivered human. Tactile stimulation is considered an effective means of stimulating respiration in the newly born infant and is equally effective in other species. By using these methods, and by placing the animals in an environment enriched with oxygen, we were able to have nearly $100 \%$ survival in control animals delivered at 27.5-28.5 days of gestation, ages at which mortality has been reported to approach $100 \%$.

Motoyama and his co-investigators (15) placed prematurely delivered rabbits on a warm blanket but did not report further stimulation. Taeusch and his co-investigators (21) delivered their animals between 27.9 and 28.3 days of gestation into an environment of $24^{\circ}, 40 \%$ humidity, and an $\mathrm{F}_{1} \mathrm{O}_{2}$ of 0.21 with no stimulative or resuscitative measures. These differences in management probably explain the better survival in this study than has been reported previously.

Within the first $30 \mathrm{~min}$ after delivery most animals showed signs of respiratory distress, and during this period one could not easily distinguish those which would die early from those which would survive for the duration of the study. With continued survival, color and tone improved during the second 30min period; gasping and irregular respirations became regular, and the majority of survivors at $60 \mathrm{~min}$ were not cyanotic and had minimal, if any, clinical signs of respiratory distress. The differences in survival between the three groups are not well explained. The $50 \%$ survival time for the control group was 30 min, and at $30 \mathrm{~min} 75 \%$ of the cortisol and $94 \%$ of the aminophylline-treated groups were alive. These relationships persisted throughout the study, although by $60 \mathrm{~min}$ the survival rate of the cortisol-treated group was identical to the controls, $22.2 \% ; 52.9 \%$ of the aminophylline-treated group was alive. The hydrocortisone-treated group surviving to $60 \mathrm{~min}$ had a smaller total lung volume than the control and aminophyllinetreated groups. In addition, a smaller percentage of retained volume at both 4 and $10 \mathrm{~cm} \mathrm{H}_{2} \mathrm{O}$ was present in the late survivors in the control and hydrocortisone groups than the aminophylline group. The lower lung volume observed in the cortisol-treated animals is possibly explained by poor lung growth during the treatment period, although in a study with antenatal treatment identical to the present study, lung DNA concentrations and wet weight/dry weight ratios were not significantly different in the control and cortisol-treated groups (8). Motoyama and his co-investigators (15) reported no maturational effects upon fetal rabbit lungs when cortisol in large doses was administered to the pregnant rabbit doe, but improved neuromuscular activity, lung expansion, and bubble stability from lung lavage fluid when cortisol was administered directly into the fetuses. The dose of cortisol which we administered in the present study is the same as that previously reported to be associated with increased incorporation of choline and methionine into phosphatidyl choline (2), and we cannot explain differences of lung volumes and stability we observed. The increased surface activity of the lungs of the aminophyllinetreated group which retained significantly more air at low pressures than either the control or cortisol-treated group of animals was the most striking finding of the present study. This effect probably reflects increased surface-active material at the alveolus in the aminophylline-treated animals, and correlates with the recovery of significantly more phosphatidylcholine in the lavage fluid of the aminophylline-treated animals which survived for $60 \mathrm{~min}$, although an equal proportion of the phosphatidylcholine was present with palmitate as the fatty acid component in the three groups.

We have previously presented evidence supporting the postulate that cortisol and aminophylline augment synthesis of phosphatidylcholine through similar mechanisms involving augmentation of cyclic AMP levels by inhibition of cyclic AMP phosphodiesterase (2). Differences we observed between cortisol and aminophylline-treated animals are not fully understood. Even though both agents appear to augment phosphatidylcholine synthesis through a cyclic AMP associated-mechanism they would be expected to have many widely differing effects on different tissues. Although glucocorticoids in physiologic as well as pharmacologic concentration inhibit cyclic AMP phosphodiesterase activity $(12,17)$, their major effects are exerted through regulation (generally inhibition) of protein synthesis through regulation of DNA-directed RNA synthesis (24). This mechanism involves initial interaction of the glucocorticoid with a cytosol receptor and translocation of this reaction complex to the nucleus (16). Aminophylline would not be expected to react with the cell genome in this way. Inhibition of fetal lung growth by glucocorticoids may be a feature of the generalized catabolic effect of glucocorticoids (14). Another important difference in the modes of action of these two agents has to do with the well recognized stimulatory effect of methyl xanthines on respiration, which has been demonstrated to occur in the prematurely born human infant $(18,22)$. It is possible that the peripheral effects on the lungs of aminophylline are augmented by stimulation of the central nervous system, promoting respiration, and that this combination of effects is related to enhanced survival of newly born animals.

Our data with respect to control animals are similar to those of Taeusch and his co-investigators (21), who reported improved lung compliance associated with prolonged survival in prematurely delivered animals. Fujiwara and his associates (7) reported that alveolar phospholipids double after $10 \mathrm{~min}$ of breathing and continue to increase up to $48 \mathrm{hr}$ of age without changes in the quality of the phospholipids.

The difference in mortality rate between the cortisol and 
aminophylline-treated animals is not known. To our knowledge cortisol effects on survival have not been studied in rabbits delivered at 27.0 days.

\section{CONCLUSION}

It appears likely that aminophylline is at least as effective as cortisol (and possibly more so) in accelerating maturation of fetal lungs as evidenced by survival time, phosphatidylcholine content, and lung pressure-volume characteristics. Toxicity of aminophylline administered prenatally to the mother has not been investigated, but in the present study no major evidence of fetal toxicity was observed.

\section{REFERENCES AND NOTES}

1. Arvidson, G. A. E.: Structural and metabolic heterogeneity of rat liver glycerophosphatides. Eur. J. Biochem., 4: 478 (1968).

2. Barrett, C. T., Sevanian, A., Lavin, N., and Kaplan, S. A: Role of adenosine $3^{\prime}, 5^{\prime}$-monophosphate in maturation of fetal lungs. Pediat. Res., 10: 621 (1976).

3. Bartlett, G. R.: Phosphorus assay in column chromatography. J. Biol. Chem., 234: 466 (1959).

4. Budin, P.: Le nourrisson, alimentation et hygiene des enfants delilés-enfants nés à term (Octave Doin, Paris, 1900).

5. Carson, S. H., Taeusch, H. W., and Avery, M. E.: Inhibition of lung cell division after hydrocortisone injection into fetal rabbits. J. Appl. Physiol., 34: 660 (1973)

6. Folch, J., Lees, M., and Sloan-Stanley, G. H.: A simple method for isolation and purification of total lipids from animal tissues. J. Biol. Chem., 226: 497 (1957).

7. Fujiwara, T., Adams, F. H., El-Salawy, A., and Sipos, S.: "Alveolar" and whole lung phospholipids of newborn lambs. Proc. Soc. Exp. Biol. Med. 127: 962 (1968).

8. Gilden, C., Sevanian, A., Tierney, D. F., Kaplan, S. A., and Barrett, C. T.: Regulation of fetal lung phosphatidyl choline synthesis by cortisol: Role of glycogen and glucose. Pediat. Res., 11: 845 (1977).

9. Howard, E.: Reductions in size and total DNA of cerebrum and cerebellum in adult mice after corticosterone treatment in infancy. Exp. Neurol., 22: $191,(1968)$.

10. Karotkin, E. H., Kido, M., Cashore, W. J., Redding, R. A., Douglas, W. J., Stern, L., and Oh, W.: Acceleration of fetal lung maturation by aminophyl- lin in pregnant rabbits. Pediat. Res., 10: 722 (1976).

11. Kotas, R. V., Mims, L. C., and Hart, L. K.: Reversible inhibition of lung cell number after glucocorticoid injection into fetal rabbits to enhance surfactant appearance. Pediatrics, 53: 358 (1974).

12. Lavin, N., Rachelefsky, G., and Kaplan, S. A.: Inhibition of cyclic AMP phosphodiesterase in human lymphocytes by physiological concentrations of hydrocortisone. Horm. Metab. Res., 7: 253 (1975).

13. Liggins, G. C., and Howie, R. N.: A controlled trial of antepartum glucocorticoid treatment for prevention of the respiratory distress syndrome in premature infants. Pediatrics, 50: 515 (1972).

14. carbohydrate metabolism. Endocrinology, 26: 309 (1940).

15. Motoyama, E. K., Orzalesi, M. M., Kikkawa, Y., Kaibara, M., Wu, B. Zigas, C. J., and Cook, C. D.: Effect of cortisol on the maturation of fetal rabbit lungs. Pediatrics, 48: 547 (1971).

16. Rousseau, G. G., Higgins, S. J., Baxter, J. D., Gelfand, D., and Tomkins, G. M.: Binding of glucocorticoid receptors to DNA. J. Biol. Chem., 250: 6015 (1975).

17. Schmidtke, J., Wienker, T., Flugel, M., and Engel, W.: In vitro inhibition of cyclic AMP phosphodiesterase by cortisol. Nature, 262: 593 (1976).

18. Shannon, D. C., Gotay, F., Stein, I. M., Rogers, M. C., Todres, I. D., and Moylan, F. M. B.: Prevention of apnea and bradycardia in low-birthweight infants. Pediatrics, 55: 589 (1975).

19. Shapiro, S. Some physiologic, biochemical and behavioral consequences of neonatal hormone administration: Cortisol and thyroxin. Gen. Comp. Endocrinol., 10: 214 (1968).

20. Snedecor, G. W., and Cochran, W. G.: Statistical Methods, Ed. 6 (Iowa State University Press, Ames, Iowa, 1967).

21. Taeusch, H. W. Jr., Heitner, M., and Avery, M. E.: Accelerated lung maturation and increased survival in premature rabbits treated with hydrocortisone. Amer. Rev. Resp. Dis., 105: 971 (1972)

22. Uauy, R., Shapiro, D. L., Smith, B., and Warshaw, J. B.: Treatment of severe apnea in prematures with orally administered theophylline. Pediatrics, 55: 595 (1975).

23. Wellman, K. F., and Volk, B. W.: Fine structural changes in the rabbit placenta induced by cortisone. Arch. Pathol., $94: 147$ (1972).

24. Wicks, W. D.: The mode of action of glucocorticoids. In: Biochemistry of Hormones, M. T. P. International Review of Science, Biochemistry, Series 1, Vol. 8, pp. 211-242 (University Park Press, Baltimore, 1974).

25. This research was supported in part by a grant from the California Research and Medical Education Fund of the California Lung Association.

26. Requests for reprints should be addressed to: Cynthia T. Barrett, M.D., Department of Pediatrics, UCLA School of Medicine, Los Angeles, CA 90024 (USA).

27. Received for publication January 10,1977

28. Accepted for publication March 28, 1977.

\title{
Inotropic Response of the Neonatal Canine Myocardium to Dopamine
}

\author{
DAVID J. DRISCOLL, ${ }^{(22)}$ PAUL C. GILLETTE, EDWARD G. EZRAILSON, AND ARNOLD \\ SCHWARTZ \\ Departments of Cell Biophysics and Pediatrics, Section of Cardiology, Baylor College of Medicine; Texas \\ Children's Hospital; and The Fondren-Brown Cardiovascular Center of The Methodist Hospital, Houston, Texas,
}

\section{Summary}

The inotropic responsiveness of the developing myocardium to dopamine and isoproterenol was evaluated using isolated, perfused ventricles and atrial strips from puppies ages $15 \mathrm{hr}$ to 33 days. Responses were compared to those in adult animals.

The maximum percentage of increase of left ventricular $\mathrm{dF} / \mathrm{dt}$ increased from $12 \pm 5$ (mean \pm SEM) at 0-7 days $(n=6)$ to $100 \pm 40$ at 21-33 days $(n=3)$ of postnatal age. At 7-14 days $(n=4)$ and 15-20 days $(n=5)$ of age the maximum percentage of increase of left ventricular $\mathrm{dF} / \mathrm{dt}$ was $28 \pm 10$ and $39 \pm 17$, respectively. Puppy ventricle responded to isoproterenol at all ages equally (maximum percentage increase of left ventricular $\mathrm{dF} / \mathrm{dt}=46 \pm 13)$. 